Prepared for the U.S. Department of Energy

under Contract DE-AC05-76RL01830

\title{
Testing the Floor Scale Designated for Pacific Northwest National Laboratory's UF 6 Cylinder Portal Monitor
}

MM Curtis

DR Weier

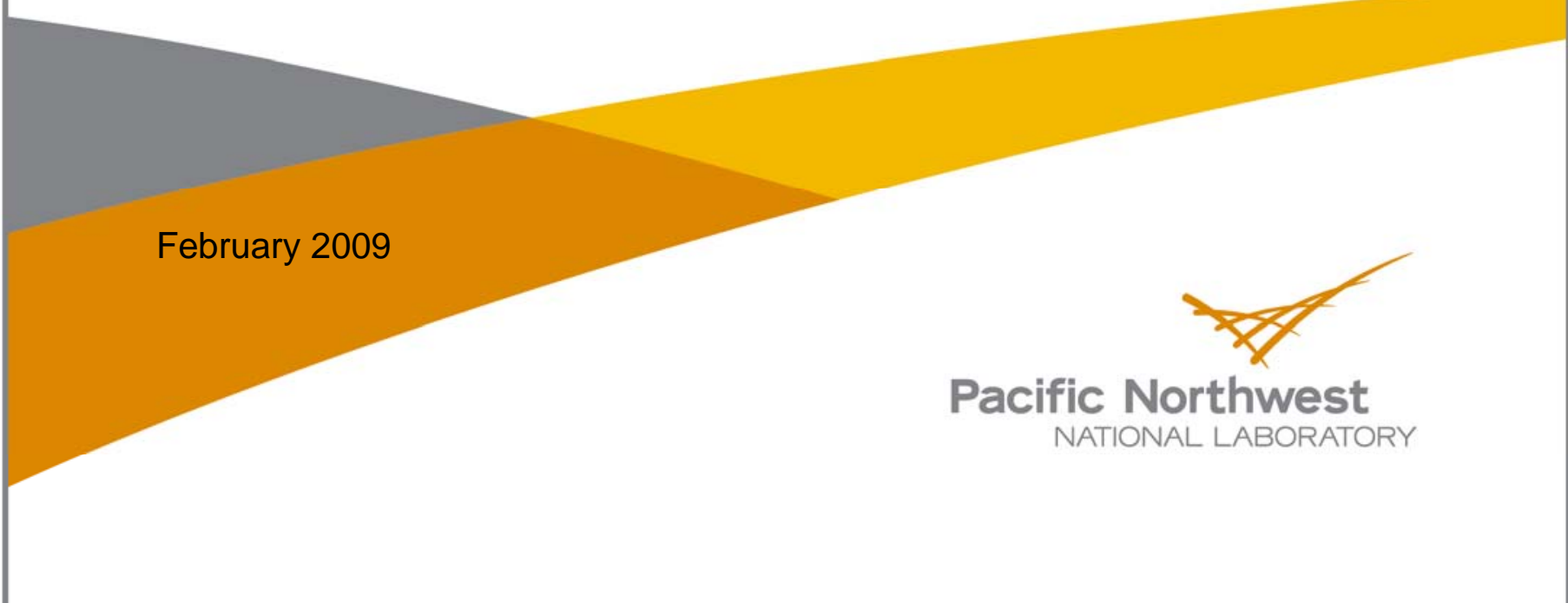




\title{
DISCLAIMER
}

This report was prepared as an account of work sponsored by an agency of the United States Government. Neither the United States Government nor any agency thereof, nor Battelle Memorial Institute, nor any of their employees, makes any warranty, express or implied, or assumes any legal liability or responsibility for the accuracy, completeness, or usefulness of any information, apparatus, product, or process disclosed, or represents that its use would not infringe privately owned rights. Reference herein to any specific commercial product, process, or service by trade name, trademark, manufacturer, or otherwise does not necessarily constitute or imply its endorsement, recommendation, or favoring by the United States Government or any agency thereof, or Battelle Memorial Institute. The views and opinions of authors expressed herein do not necessarily state or reflect those of the United States Government or any agency thereof.

\author{
PACIFIC NORTHWEST NATIONAL LABORATORY \\ operated by \\ BATTELLE \\ for the \\ UNITED STATES DEPARTMENT OF ENERGY \\ under Contract DE-AC05-76RL01830
}

Printed in the United States of America
Available to DOE and DOE contractors from the Office of Scientific and Technical Information,
P.O. Box 62, Oak Ridge, TN 37831-0062;
ph: (865) 576-8401
fax: $(865)$ 576-5728
email: reports@adonis.osti.gov

\begin{abstract}
Available to the public from the National Technical Information Service, U.S. Department of Commerce, 5285 Port Royal Rd., Springfield, VA 22161 ph: (800) 553-6847 fax: $(703) 605-6900$ email: orders@ntis.fedworld.gov online ordering: http://www.ntis.gov/ordering.htm
\end{abstract}

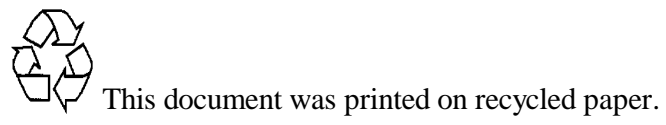




\section{Testing the Floor Scale Designated for Pacific Northwest National Laboratory's UF $_{6}$ Cylinder Portal Monitor}

MM Curtis

DR Weier

February 2009

Prepared for the

U.S. Department of Energy

under Contract DE-AC05-76RL01830

Pacific Northwest National Laboratory

Richland, Washington 99352 


\section{Contents}

1.0 Testing the Floor Scale 1

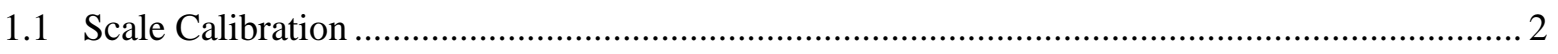

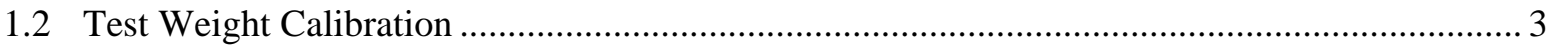

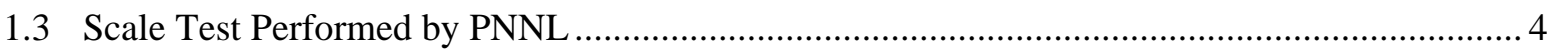

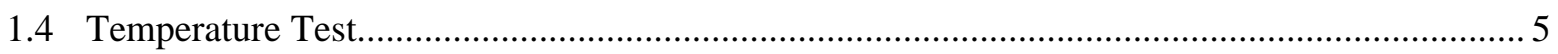

2.0 Summary/Conclusions $\quad 6$

3.0 Appendix $\quad 8$

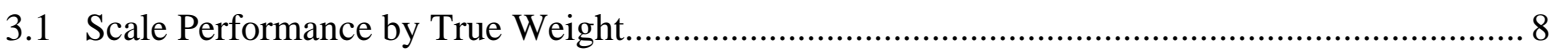

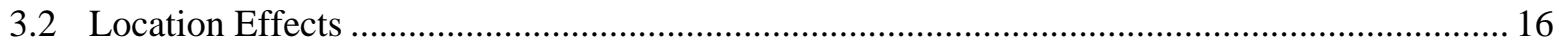

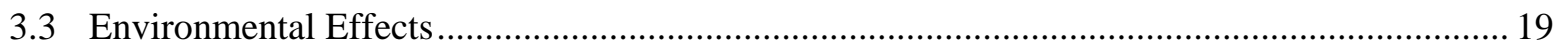

$\begin{array}{llr}4.0 & \text { References } & 20\end{array}$

\section{Figures}

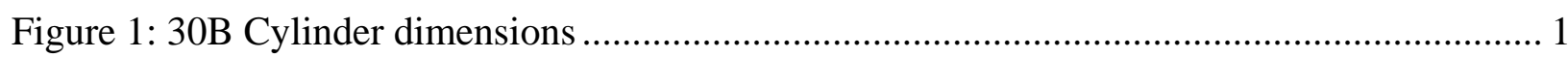

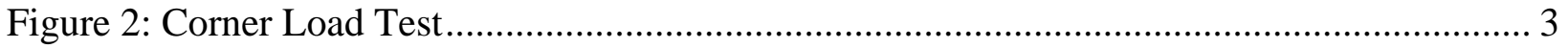

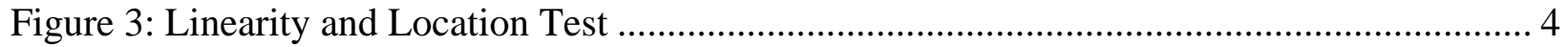

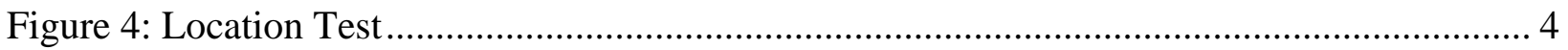

Figure 5: Mean and Standard Deviations for Each True Weight.......................................... 13

\section{Tables}

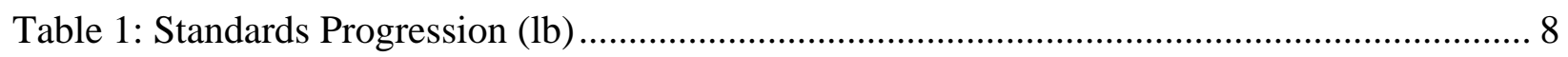

Table 2: Means and Standard Deviations by True Weight ..................................................... 9

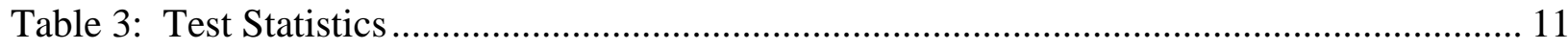

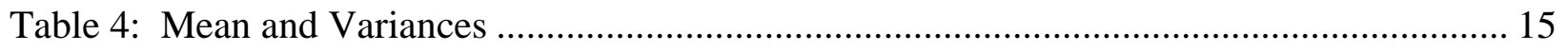

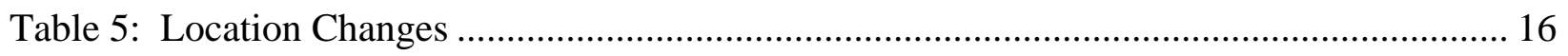

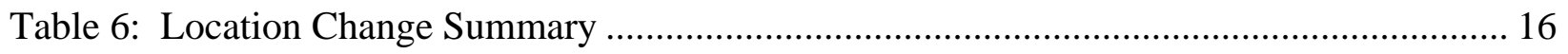

Table 7: Oneway Analysis of Absolute Difference by Location............................................ 18

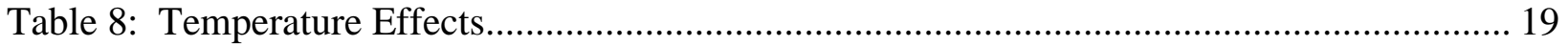




\subsection{Testing the Floor Scale}

Pacific Northwest National Laboratory (PNNL) obtained a Mettler Toledo floor scale for the purpose of testing it to determine whether it could replace the International Atomic Energy Agency's (IAEA) cumbersome, hanging load cell. The scale is intended for use as a subsystem within PNNL's nascent UF 6 Cylinder Portal Monitor. The particular model was selected for its accuracy, size, and capacity. The intent will be to use it only for 30B cylinders; consequently, testing did not proceed beyond 8,000 lb. Scale specifications are listed below.

Floor scale: Mettler-Toledo Model 2158-02054-A

- Diamond Treadplate Mild Steel Platform 4' x 6' x 4"

- Gross Capacity 10,000 lb.

- Readout $=10,000 \times 1 \mathrm{lb} / 5,000 \times 0.5 \mathrm{~kg}$

- Four 5,000 kg Stainless Steel Hermetically Sealed Load Cells

- Stainless Steel Junction Box

- Stainless Steel Rocker Pin Suspension

- Guaranteed Accuracy 1:5000

- 25' Cable to Terminal

- Shipping Weight $700 \mathrm{lb}$

Terminal: Mettler-Toledo INB560

Ultimately the scale will be used to measure 30B cylinders (described in ANSI N14.1, Uranium Hexafluoride Packaging for Transport) containing uranium hexafluoride. These cylinders have a nominal tare weight of 1,400 lb and a maximum net weight of 5,020 lb. Adding the weight of the cart or sled it is riding on, gives a range of interest of $\sim 1,800-7,000 \mathrm{lb}$.

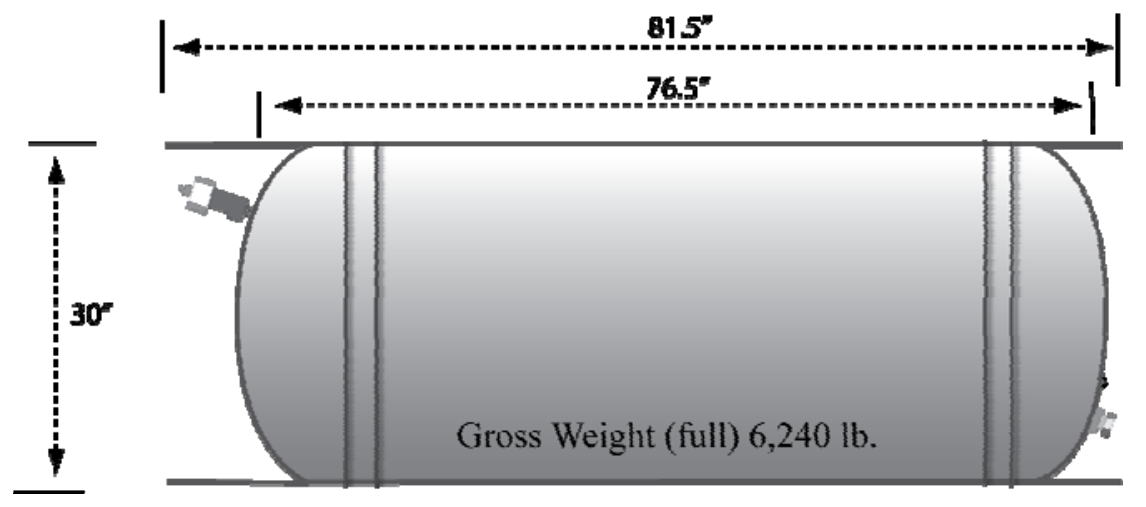

Figure 1: 30B Cylinder dimensions

With regard to the portal monitor, the decision was made to focus prototype efforts only on 30" product cylinders for the following reasons:

- UF6 product is sometimes contained in 48" cylinders, but these are used only for internal transfers-not shipments.

- Feed and tail cylinders are routed separately from product cylinders

- Optimizing for smaller 30B cylinders places the enrichment panels closer to the source of radiation

- The scale will be more accurate if calibrated over a smaller range

- It is cheaper to design a prototype to handle one type of cylinder 
A plant where PNNL has performed cylinder testing in the past uses a similar floor scale to measure 30B cylinders with high accuracy. In their setup, the scale is housed in a temperature-controlled, outdoor shed. Cylinders are taken singly from the storage yard into the shed where weighing and assay measurements are performed. Any cylinder that differs by more than $2 \mathrm{~kg}$ from the declared weight is considered suspect. A working standard is used before each batch to verify the calibration.

The IAEA's portable load-cell-based weighing system (LCBS) was developed for the Agency by the U.S. National Bureau of Standards through the U.S. Program of Technical Assistance to IAEA Safeguards (POTAS). The Agency's load cell is portable and capable of weighing 10-15 cylinders an hour. It has a declared accuracy of 1:3,000, but this is rarely attained in the field. Partly this is due to the fact that the device takes a good deal of abuse in the field and is not always maintained properly. Flexures, attached above and below the load cell are bulky and are not always employed, resulting in further inaccuracies.

\subsection{Scale Calibration}

Steve Loomis of Mettler-Toledo tested the calibration of the scale using the methods outlined in NIST Handbook 44 on October 27, 2008. He used 1,000 lb. reference weights for his testing. ${ }^{1}$ A linearity and hysteresis test was performed in 8 steps. $^{2}$ The scale was zeroed and then successively loaded to 2,000, $4.000,6,000$, and $8,000 \mathrm{lb}$. It was then unloaded in 2,000 lb increments back to zero. All measured readings were within $\pm 1 \mathrm{lb}$. of the declared weight.

Weight Applied Indicated Reading

(lb)

0

2,000

4,000

6,000

8,000

6,000

4,000

2,000

0 (lb)

0

2,000

4,000

6,001

8,001

6,001

4,000

2,000

0

A corner load test was performed immediately after the calibration to determine the effect of successively shifting an applied weight of 4,000 lb between all four quadrants. The scale measured 4,000 lb in two positions and 4,001 $\mathrm{lb}$ in the other two.

1 Weight set No. TT28901 1000 lb Ca, NIST Traceability No. OR-08-223-F, Class ASTM/OIML NIST F, Calibration Date 9/9/2008. All were within 28 grams of their nominal weight at their last calibration, an ODA Hawthorne lab test on September 9, 2008.

2. Linearity refers to the quality of delivering identical sensitivity throughout the range of the scale. It is tested by weighing objects separately and then together. Hysteresis refers to different indications resulting from the direction of loading_increasing or decreasing. 


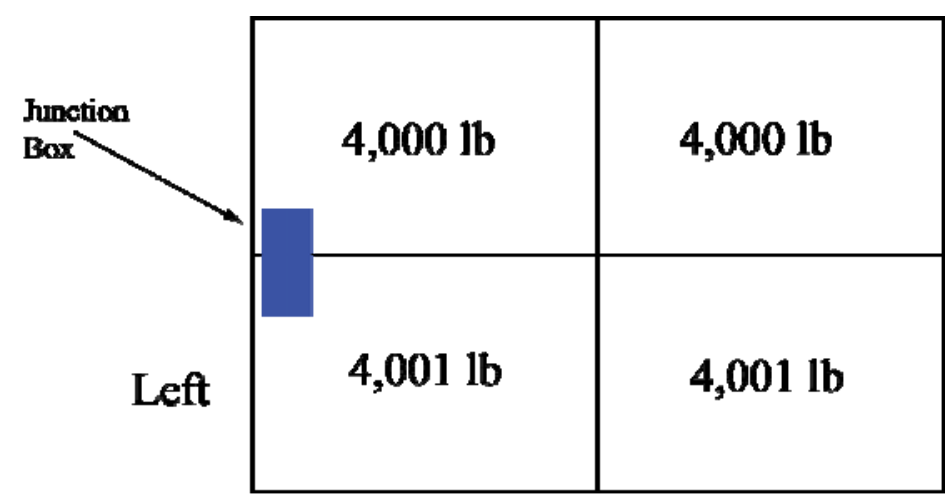

Front

Figure 2: Corner Load Test

A repeatability test was performed by placing $8,000 \mathrm{lb}$ on the scale, removing it, and then reapplying it.

$\begin{array}{rc}\begin{array}{c}\text { Weight Applied } \\ \text { (lb) }\end{array} & \begin{array}{c}\text { Indicated } \\ \text { (lb) }\end{array} \\ 8,000 & 8,000 \\ 0 & 0 \\ 8,000 & 8,001 \\ 0 & 0 \\ 8,000 & 8,000\end{array}$

The results of the Mettler Toledo test were:

Maximum Error $1 \mathrm{lb}$, allowable error $5 \mathrm{lb}$

Calculated measurement uncertainty- $1.7 \mathrm{lb}$.

The floor scale did not require any adjustments.

\subsection{Test Weight Calibration}

PNNL had six $1250 \mathrm{lb}$ test weights suitable for performing scale tests, but their weights required confirmation. Energy Northwest assayed the PNNL test weights using their now-calibrated scale on October 30, 2008. They first checked the calibration performed two days earlier using a pallet loaded with NIST "F" load weights. The pallet itself was first weighed $(50.0 \mathrm{lb})$ and then weights were loaded onto it.

While measuring the first few weights, scale drift $^{3}$ was noted. Energy Northwest compensated for the drift by reapplying their pallet of reference weights.

3. Drift is a progressive change in the number displayed on the digital readout. The weight reading does not stabilize, or unstable readings are obtained with no weight applied. The two environmental factors usually responsible are temperature and static electricity. 
All six $1250 \mathrm{lb}$. check weights were measured and the resulting values were:

- Check Weight 1: $1249.7 \mathrm{lbs} \quad$ Check Weight 2: $1251.8 \mathrm{lbs}$

- Check Weight 4: $1251.2 \mathrm{lbs} \quad$ Check Weight 5: $1249.4 \mathrm{lbs}$

- Check Weight 6: $1253.2 \mathrm{lbs} \quad$ Check Weight 8: $1250.8 \mathrm{lbs}$

The estimated uncertainty was 0.35 lbs. @ 95\% confidence, including repeatability, resolution and the reference mass uncertainty.

A significant problem noted during calibration of these weights was indicated drift over short periods of time. The cause was subsequently ascribed to the scale's location. It was directly adjacent to the roll-up door where weights were being cycled in-and-out using a forklift. The rapid temperature change had apparently affected the load cell response. The vendor frequently re-zeroed the scale, but it undoubtedly affected the calibration.

\subsection{Scale Test Performed by PNNL}

The first attempt to test the scale using the check weights calibrated by Energy Northwest was on October 31,2008 . The roll-up door was again opened to provide maneuvering room for the forklift, but the rush of cold air caused the indicated weight to shift by one pound in the first 25 minutes. A second attempt was made the following day, and this time the door remained closed throughout the procedure.

The first set of weighings were performed by placing the eight check weights in two stacks on opposite sides of the scale starting with one on the left-hand side, one on the right-hand side, the third on the left, and continuing till all eight were on the scale.

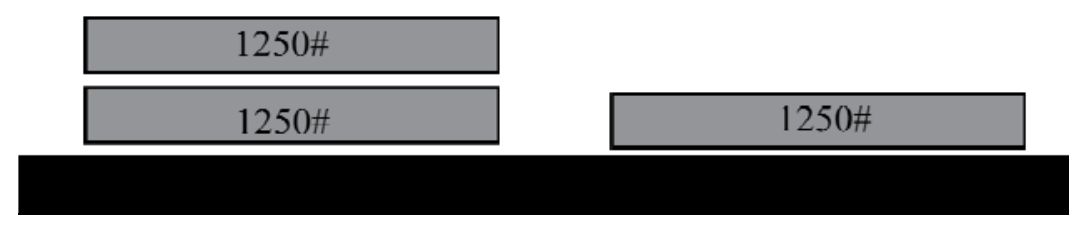

Figure 3: Linearity and Location Test

The second set of weighings was performed with the check weights by placing them in two stacks on opposite sides of the scale starting on the right-hand side.

The third set of weighings placed them all in one stack on the center of the scale.

A location test was then performed to check for corner error. Check weights ${ }^{\#} 1$ and ${ }^{\#} 2$ were alternately placed on the front and back of the scale to view the variation. A second location test was performed moving the weights from side-to-side.

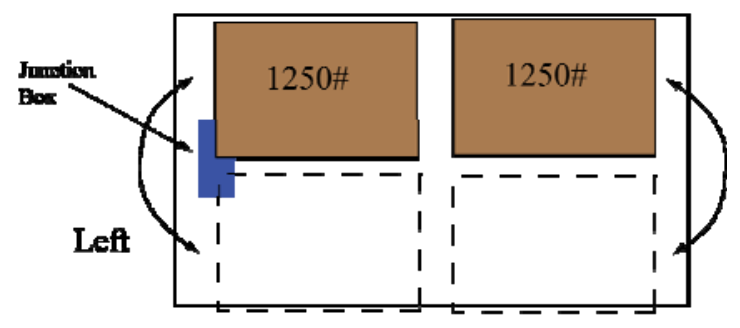

Front

Figure 4: Location Test 


\subsection{Temperature Test}

Lastly, a temperature test was performed by placing a bag of ice on each corner of the scale, directly above the individual load cells. Weights ${ }^{\#} 1$ and ${ }^{\#} 2$ were placed in the center of the scale. The results were dramatic. The indicated reading dropped about $16 \mathrm{lb}$ in twenty minutes. 


\subsection{Summary/Conclusions}

The statistical analysis of all measurements is in the appendix, but some general points should be made regarding this test. First, it was compromised by the location of the scale. The only area obtainable for testing was directly adjacent to a roll-up door, which was raised to allow for passage of the forklift carrying the test weights during the calibration check performed by Mettler-Toledo, and during the calibration of the PNNL test weights by Energy Northwest. The drift was noted while performing these activities, but there was no alternate access portal available on the cold morning that the check weights were calibrated. This resulted in inaccurate check weight values; although, the inaccuracy was slight and probably represents real-world conditions better than the more accurate values that could have been obtained from a careful laboratory test.

IAEA guidance in International Target Values 2000 for Measurement Uncertainties in Safeguarding Nuclear Materials, ESARDA Bulletin No. 31, suggests random and systematic, relative one-sigma uncertainty estimates of $0.05 \%$ for weights. The random relative error standard deviation can be readily used as an estimate of one-sigma relative random uncertainty. (Oftentimes the observed relative bias is taken to be a one-sigma estimate of relative systematic uncertainty.) In this manner the respective relative and systematic relative uncertainties based on this loading study are $0.020 \%$ and $0.057 \%$. The random component is well within the IAEA load cell idealized value while the systematic component is slightly high.

In spite of the temperature-related errors that generated the larger systematic component in the study, the scale is quite accurate as demonstrated by Mettler-Toledo a few days prior to the PNNL test when weather conditions were more clement. The systematic error falls slightly short of the International Target Values for IAEA/EURATOM load cells, but those values are idealized numbers obtainable in carefully controlled settings, but they are not achieved routinely in the field, especially in outdoor locations.

Analysis during the scale qualification study resulted in the following observations.

1) Averaged over all true weight levels, the absolute error mean/bias and standard deviation were respectively $2.18 \mathrm{lb}$. and $0.78 \mathrm{lb}$. The latter could be used as a one-sigma absolute random uncertainty in variance propagation applications, and the former as a one-sigma absolute systematic uncertainty.

2) Averaged over all true weight levels, the relative error mean/bias and standard deviation were respectively $0.057 \%$ and $0.020 \%$. The latter could be used as a one-sigma relative random uncertainty in variance propagation applications, and the former as a one-sigma relative systematic uncertainty.

3) For the relative case under the previous point, the magnitude of the estimated random uncertainty is less than the IAEA target value $0.05 \%$, that is, for a relative random error one-sigma uncertainty. However, the estimated systematic uncertainty is larger than that same IAEA target value for systematic uncertainty, and the systematic being nearly three times as great as the random is disconcerting. It is clearly due to a persistent positive bias. (See the discussion on the outside temperatures and roll-up door above.)

4) The measurement error variability was partially due to differences caused by a) the various magnitudes of the true weights measured, $b$ ) whether the odd standard (when an odd number of standards was used) was placed on the left stack, the right stack, or the center, and c) whether the last standard moved prior to weighing was added or removed. If these sources of variability were held at constant levels, then the random uncertainty estimates above would be reduced by about two-thirds. 
5) For the true weight range from about 4000 to 8000 pounds, the most appropriate error models based on these measurements would result in a one-sigma relative random uncertainty of about $0.01 \%$, and a one-sigma absolute systematic uncertainty of about $2.5 \mathrm{lb}$. At lesser weights appropriate error modeling is not as obvious.

6) In examining performance at different platform locations, little difference was observed from side-to-side or on the front of the platform, but measurements were about a pound less at the back location.

7) Placing ice on the scale platform had a dramatic effect on weighings over the time the ice was there. In about 15 minutes the absolute measurement bias dropped from $+2.5 \mathrm{lb}$. to about $-14.0 \mathrm{lb}$ and then remained constant at that level for about another ten minutes, at which time the measuring ceased.

Overall, the Mettler-Toledo load cell performance was accurate, but it is apparent that it cannot be used in an area that experiences rapid temperature changes over short periods of time. The hanging load cells the IAEA and Euratom currently use also drift with temperature when used outdoors or in an open bay, but inspectors zero it between each cylinder measurement, or about every three minutes. Since the portal monitor load cell will be used in unattended mode, the IAEA cannot depend on frequent re-zeroing of the scale.

From an operator's perspective there is no advantage to using either a hanging load cell or a floor scale. Both require his participation, but there is less risk to the cylinders if they do not have to be held in the air for the duration of each measurement. 


\subsection{Appendix}

\subsection{Scale Performance by True Weight}

Table 1gives the weights recorded as standards were added or removed. Units are in pounds. Six different groupings of standards were generated in this manner, and they are given in the first column. The associated "true weights" are then given in the second column. The same progression of adding and removing standards was followed in each of the three sections of that table top to bottom; this sequence was specified in the proposed procedure.

When an even number of standards were used, they were placed in two even stacks from left to right on the scale platform and centered front to back. When an odd number of standards were used, the odd one was placed on the left-hand stack in the top of the three groupings; on the right-hand stack in the center grouping; and centered on the platform/stacks in the bottom grouping.

\begin{tabular}{|c|c|c|c|c|}
\hline $\begin{array}{l}\text { Standards } \\
\text { Included }\end{array}$ & $\begin{array}{c}\text { True } \\
\text { Weight }\end{array}$ & \multicolumn{3}{|c|}{ Weighings (LHS weight added first) } \\
\hline 1 & 1249.7 & 1250.7 & 1250.2 & 1250.2 \\
\hline 1,2 & 2501.5 & 2503.1 & 2502.7 & 2503 \\
\hline $1,2,6$ & 3754.7 & 3757 & 3756.8 & 3756.8 \\
\hline $1,2,6,8$ & 5005.5 & 5008 & 5007.9 & 5008 \\
\hline $1,2,6,8,4$ & 6256.7 & 6258.7 & 6258.7 & 6258.6 \\
\hline $1,2,6,8,4,5$ & 7506.1 & 7507.9 & 7507.9 & 7507.9 \\
\hline $\begin{array}{l}\text { Standards } \\
\text { Included }\end{array}$ & $\begin{array}{c}\text { True } \\
\text { Weight }\end{array}$ & \multicolumn{3}{|c|}{ Weighings (RHS Weight added first) } \\
\hline 1 & 1249.7 & 1251 & 1250.6 & 1250.6 \\
\hline 1,2 & 2501.5 & 2503.5 & 2503.2 & 2503.6 \\
\hline $1,2,6$ & 3754.7 & 3757.2 & 3757.1 & 3757.1 \\
\hline $1,2,6,8$ & 5005.5 & 5008.2 & 5008.2 & 5008.3 \\
\hline $1,2,6,8,4$ & 6256.7 & 6259 & 6259 & 6259 \\
\hline $1,2,6,8,4,5$ & 7506.1 & 7508.4 & 7508.3 & 7508.3 \\
\hline $\begin{array}{l}\text { Standards } \\
\text { Included }\end{array}$ & $\begin{array}{c}\text { True } \\
\text { Weight }\end{array}$ & \multicolumn{3}{|c|}{ Weighings (all centered) } \\
\hline 1 & 1249.7 & 1250.9 & 1250.7 & 1250.7 \\
\hline 1,2 & 2501.5 & 2503.7 & 2503.5 & 2503.6 \\
\hline $1,2,6$ & 3754.7 & 3757.6 & 3757.6 & 3757.6 \\
\hline $1,2,6,8$ & 5005.5 & 5008.9 & 5008.8 & 5008.8 \\
\hline $1,2,6,8,4$ & 6256.7 & 6260 & 6260 & 6260 \\
\hline $1,2,6,8,4,5$ & 7506.1 & 7509.6 & 7509.6 & 7509 \\
\hline
\end{tabular}

Table 1: Standards Progression (lb) 
"Absolute differences" are computed from the previous table by subtracting the true weights from the weighing results. Ideally these "errors" would be close-to and average zero indicating no measurement bias. "Relative differences" are computed from the absolute differences by dividing by the true weight and multiplying by 100. That is, they are the measurement errors expressed as a percent of the true weight.

The following table gives the mean (bias) and standard deviation for each group of 9 measurements for each standard grouping (that is, for each true weight). The 9 values are obtained by combining the three sections of the previous table. Again the units for the absolute difference mean and standard deviation are pounds; and for the relative difference mean and standard deviation, the units are percent. So at the smallest true weight, in the first row of the table, the mean absolute difference for the nine measurements was 0.92 pounds with a standard deviation of 0.27 pounds. Thus the scale was reporting larger values than the true weight for a positive bias on average. This could be an inaccuracy in the scale or in the stated values of the standards. Similarly, for the relative differences, the bias is $0.074 \%$ with a standard deviation of $0.022 \%$.

The final column expresses the magnitude of the bias relative to the variability observed in the various groups. This is a t-distribution value that indicates the "statistical significance" of the mean bias. A value of about 3.0 or more (or -3.0 or less for a negative bias) for a t-distribution value would indicate a statistically significant bias. Since the values here range from about 10 to 22 , the biases at each true weight are all statistically quite significant.

\begin{tabular}{|c|c|c|c|c|c|c|c|}
\hline $\begin{array}{c}\text { True } \\
\text { Weight }\end{array}$ & $\begin{array}{c}\text { Number } \\
\text { of Values }\end{array}$ & $\begin{array}{c}\text { Mean } \\
\text { Measured } \\
\text { Value }\end{array}$ & $\begin{array}{c}\text { Mean } \\
\text { Abs Diff }\end{array}$ & $\begin{array}{c}\text { Standard } \\
\text { Deviation } \\
\text { Abs Diff }\end{array}$ & $\begin{array}{c}\text { Mean Rel } \\
\text { Diff }\end{array}$ & $\begin{array}{c}\text { Standard } \\
\text { Deviation } \\
\text { Rel Diff }\end{array}$ & $\begin{array}{c}\text { t-dist } \\
\text { value }\end{array}$ \\
\hline \hline 1249.7 & 9 & 1250.62 & 0.92 & 0.27 & 0.074 & 0.022 & 10.14 \\
\hline 2501.5 & 9 & 2503.32 & 1.82 & 0.34 & 0.073 & 0.014 & 16.16 \\
\hline 3754.7 & 9 & 3757.2 & 2.50 & 0.33 & 0.067 & 0.009 & 22.87 \\
\hline 5005.5 & 9 & 5008.34 & 2.84 & 0.39 & 0.057 & 0.008 & 22.01 \\
\hline 6256.7 & 9 & 6259.22 & 2.52 & 0.60 & 0.040 & 0.010 & 12.58 \\
\hline 7506.1 & 9 & 7508.54 & 2.44 & 0.69 & 0.033 & 0.009 & 10.61 \\
\hline \hline Overall & 54 & n.a. & 2.18 & 0.78 & 0.057 & 0.020 & 20.49 \\
\hline
\end{tabular}

Table 2: Means and Standard Deviations by True Weight

If differences in biases and standard deviations over the various true weight groups are ignored with all measurements grouped together, the overall absolute mean bias and standard deviation are 2.18 and 0.78 pounds respectively. The overall relative mean bias and standard deviation are 0.057 and 0.020 percent respectively. These values are shown in the final row of the table above.

IAEA guidance in International Target Values 2000 for Measurement Uncertainties in Safeguarding Nuclear Materials, ESARDA Bulletin No. 31, suggests random and systematic, relative one-sigma uncertainty estimates of $0.05 \%$ for weights. (As a former inspector, the author can state that this number is an ideal that is not often achieved in the field.) The random relative error standard deviation can be readily used as an estimate of one-sigma relative random uncertainty. And oftentimes the observed relative bias is taken to be a one-sigma estimate of relative systematic uncertainty. In this manner the respective relative and systematic relative uncertainties based on this loading study are $0.020 \%$ and 
$0.057 \%$. The random component is well within the IAEA values while the systematic component is slightly high.

However, these are again statistically significant biases as indicated by the summary information on the following page (and in the bottom right cell in the above table). In particular the red font information on the following page reflects this significance. The top numbers are again the t-distribution values while the bottom numbers are the associated "levels of significance". The smaller this latter number is, the more significant the bias. In the figures to the right, the bias would not be significant if the red vertical line were reasonably within the blue curves, which is not at all the case here.

If absolute error were considered the more appropriate performance model for the scale, that is, if the scale error were unrelated to the true weight being measured, then the absolute difference standard deviation could be used for random error variability propagation in material balance evaluations. Every weighing, regardless of the true weight being measured, would have associated with it a random uncertainty of 0.78 pounds (one-sigma). The absolute difference bias is also sometimes used as an estimate of systematic error variability. In this manner, a one-sigma bias of 2.18 would be applied to every measurement, and this would compound over the many weighings made, since it is assumed constant for all measurements made on the scale. However, having a systematic uncertainty component that is three times the random uncertainty component would be poor measurement practice. The bias is quite significant here, and corrective action to reduce it would be preferred.

If relative error were instead deemed more appropriate, then the percentage bias and standard deviation would be applied as a percent of the particular measured value obtained. This was discussed earlier in the comparison to the IAEA uncertainties. 


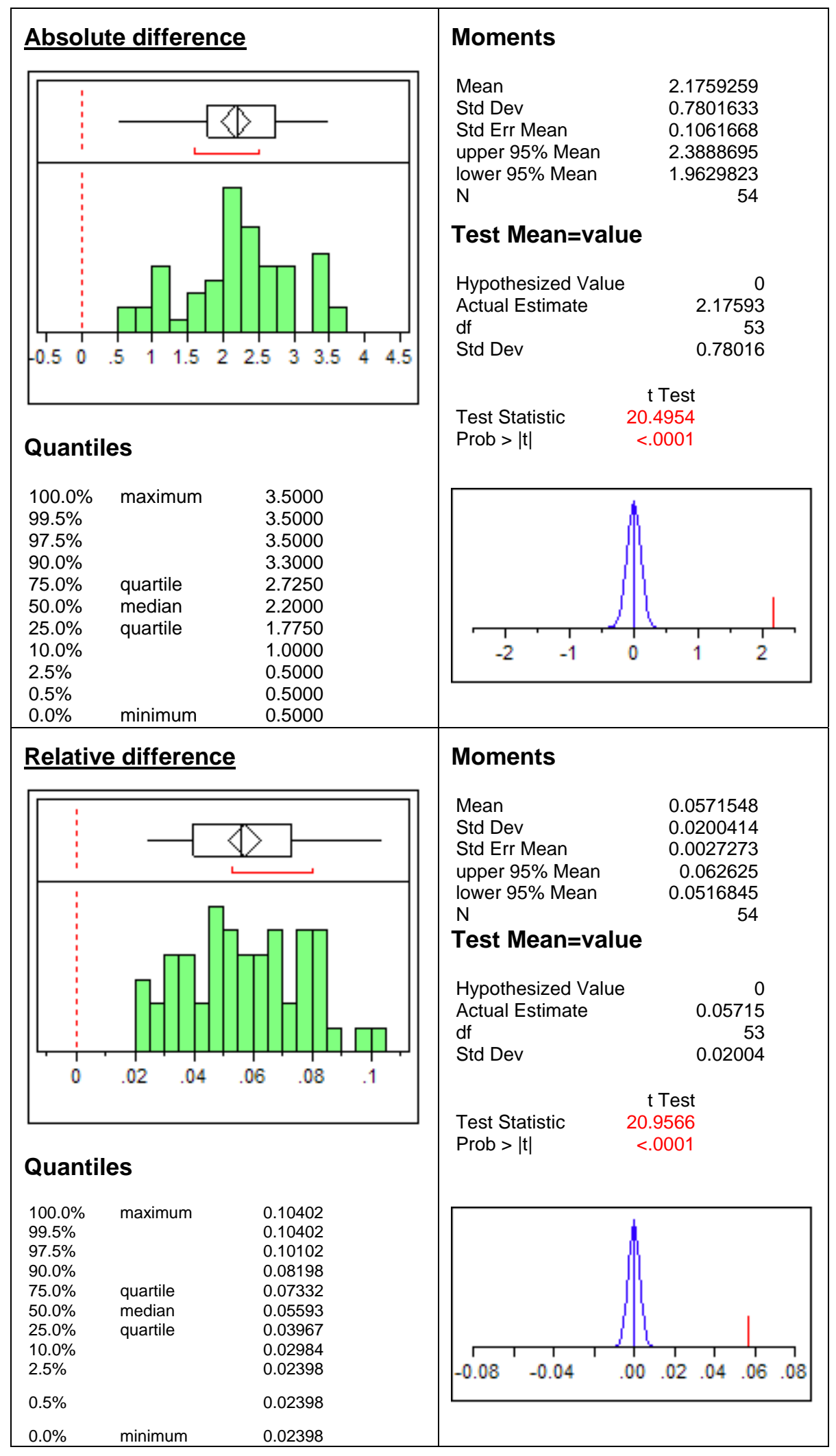

Table 3: Test Statistics 
Which absolute or relative error is the more appropriate for the scale, based on this qualification data, is addressed in the following figures where the means (biases) and standard deviations are displayed for each true weight.

At a particular site, measurement control or MC\&A personnel would have to use such information (and ongoing measurement control data) to decide how to generate measurement uncertainties for variance propagation for material balance or shipper-receiver-difference evaluations.

Scale performance is shown to be different for the 1000-3000 lb range than for the 4000-8000 lb range. If measurements are generally made in the higher range, it would be reasonable to use a relative onesigma uncertainty of $0.008 \%$ based on dashed box on the relative difference standard deviation plot (second from the top on the right). Results are pretty stable at that level for the 4000-6000 lb range.

On the other hand, an absolute one-sigma systematic uncertainty of 2.5 pounds is reasonably constant over that range as indicated by the dashed box in the top left plot.

However, different uncertainties should probably be applied if weighings are made in the lower 1000$3000 \mathrm{lb}$ range. The major issue here would be addressing the statistically significant bias. Useful information for this might be given in subsequent results shown later in this write-up for the environmental studies. 
Absolute Difference Mean (pounds)

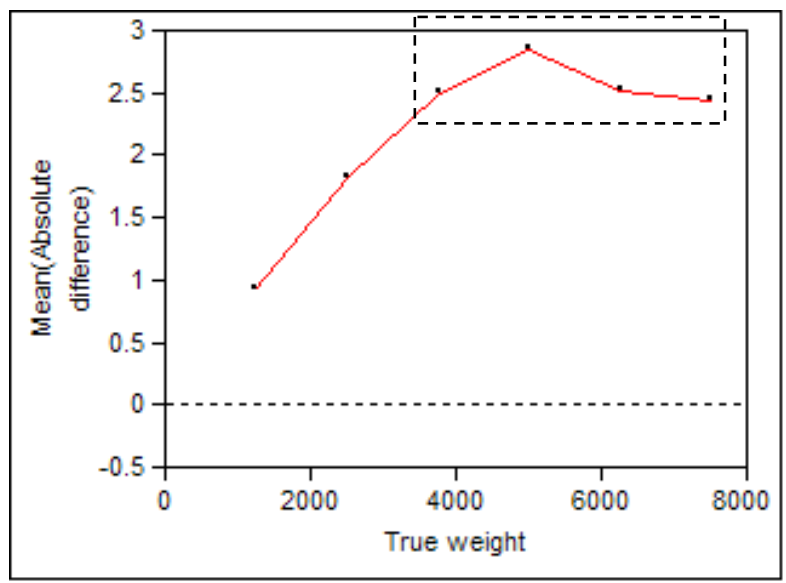

Absolute Difference Standard Deviation

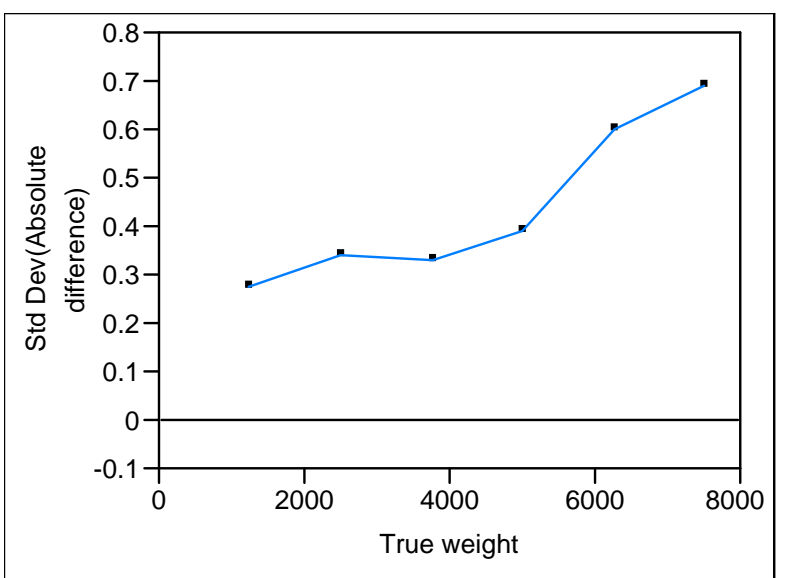

Relative difference Mean (percent)

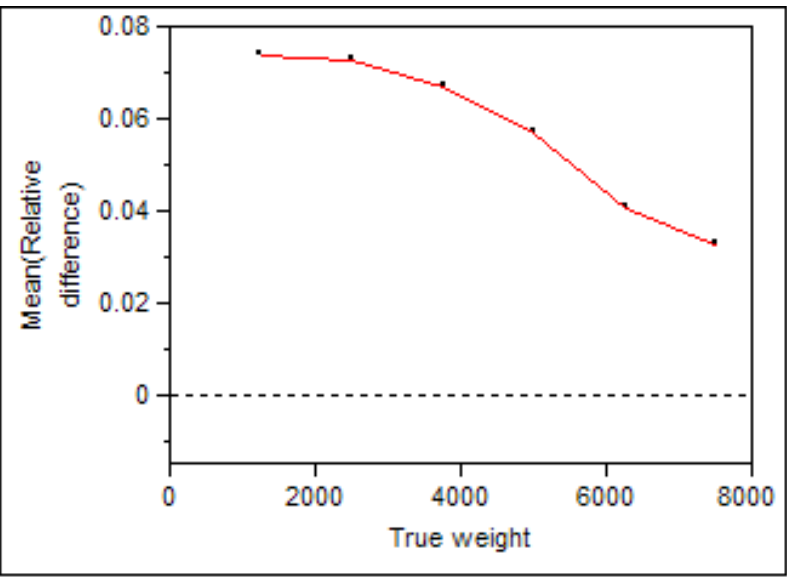

Relative difference Standard Deviation

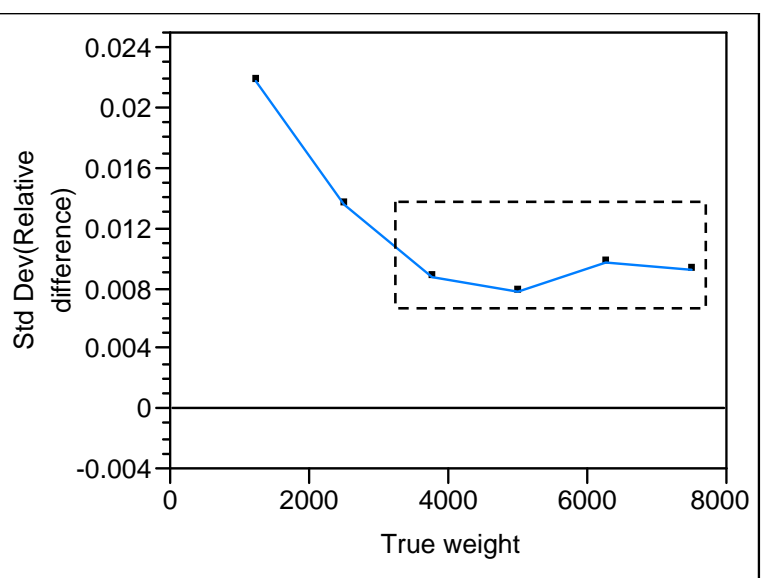

t-dist Values

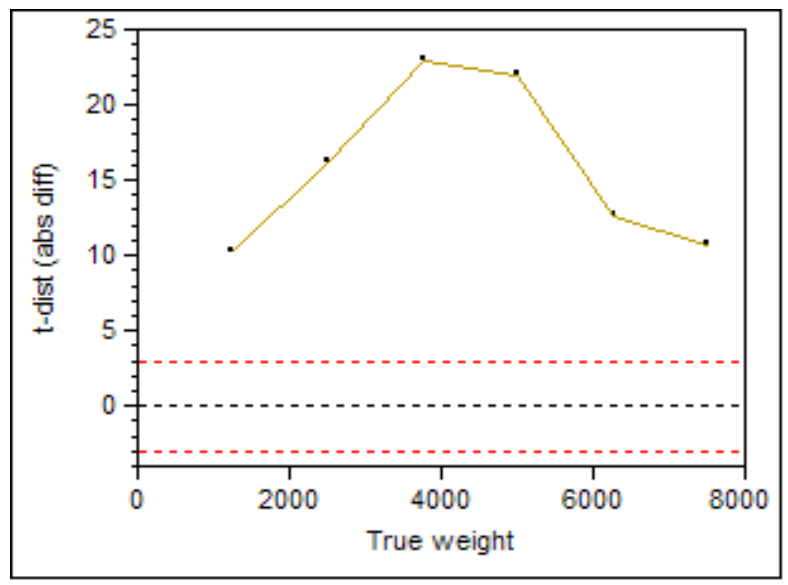

Figure 5: Mean and Standard Deviations for Each True Weight 
If the variability between the measurements we've examined were considered excessive, the modeling results on the following page could be used to identify potentially controllable factors that contribute to this variability. If some were found to be important sources of variability, their greater control could lead to less variability and reduced uncertainty estimates. In our case, our uncertainties are less than those stated by the IAEA, so the following information is not of extreme importance.

Three potential sources of variability are considered. The first is the variation between the true weight levels which has already been commented on. The second is whether the placement of the odd standard at left, center, or right makes a difference, that is, any differences between the three major areas in the Table 1. The third is whether the last standard moved was an addition to the stacks or a removal. Again such movements were specified in the proposed weighing procedure, and each weighing can thereby be identified as an addition or removal of a standard.

For absolute differences on the following page, note the cluster of red font values associated with the three factors. These are F-statistic distribution values and again their levels of significance. Since each of the F-values is relatively large, with small significance levels, each of the factors would be considered a statistically significant source of variability.

Note the first red font value 0.01594 . This is the mean-square-error of the model with these three factors, that is, the statistical variance that remains after the variability due to the three factors is removed. Its square root, the root-mean-square-error, is the associated standard deviation. This value is 0.23 pounds. This can be compared to the overall absolute difference standard deviation of 0.78 pounds discussed earlier. Thus much of that original variability is indeed explained by the variability due to these three factors. But based on the magnitudes of the F-values, the final factor (addition/removal of standards) is not as important as the true weight factor or the left/center/right location of an odd standard.

Note however that the left/center/right factor is probably confounded with time. That is, all the left's were done first, then the right's, and then the center's, if the proposed procedure was followed. And when the subsequent tables of means for this factor are considered, the means do increase from the left-hand-side to right-hand-side to center, the same order in which they were performed, so some suspicion on what actually caused these changes is warranted.

Analogously, and also on the next page, for relative differences the original standard deviation of $0.020 \%$ is reduced to the square root of 0.000051 , or $0.007 \%$. 
Absolute Difference Analysis of Variance

\begin{tabular}{lrr}
\hline Source & DF & Sum of Squares \\
Model & 8 & 29.921296 \\
Error & 45 & 2.337407 \\
C. Total & 53 & 32.258704
\end{tabular}

Mean Square

3.74016

0.05194

F Ratio

72.0060

Prob $>\mathrm{F}$

$<.0001$

\section{Effect Tests}

Source

Group

Standard Group

up/down
Sum of Squares
7.675926
20.908333
0.277778

F Ratio

73.8888

80.5059

5.3478

Group Means Table

$\begin{array}{lr}\text { Level } & \text { Mean } \\ \text { centered } & 2.66667 \\ \text { LHS first } & 1.75000 \\ \text { RHS first } & 2.11111\end{array}$

Standard Group Means Table

$\begin{array}{lr}\text { Level } & \text { Mean } \\ 1 & 0.92222 \\ 2 & 1.82222 \\ 3 & 2.50000 \\ 4 & 2.84444 \\ 5 & 2.52222 \\ 6 & 2.44444\end{array}$

up/down Squares Means Table

Level

Mean

removal

2.00000

addition

2.31667

Relative Difference Analysis of Variance

Source

Model

Error

C. Total
Sum of Squares

0.01899586

0.00229198

0.02128784
Mean Square

0.002374

0.000051

Ratio

46.6199

Prob $>$ F

$<.0001$

\section{Effect Tests}

Source

Group

Standard Group

up/down

$\begin{array}{rr}\text { Nparm } & \text { DF } \\ 2 & 2 \\ 5 & 5 \\ 1 & 1\end{array}$

F Ratio

45.9925

56.1553

15.8528
Prob $>F$

$<.0001$

$<.0001$

\section{Group Means Table}

Level

centered

LHS first

RHS first

Mean

0.068307

0.045507

0.057650

\section{Standard Group Means Table}

Level

$2 \quad 0.073795$

$3 \quad 0.066583$

$4 \quad 0.056826$

$5 \quad 0.040312$

$6 \quad 0.032566$

up/down Means Table

Level

Mean

removal $\quad 0.057638$

addition $\quad 0.056768$

Table 4: Mean and Variances 


\subsection{Location Effects}

The following weighings were done with the same set of standards but while varying locations from front to back and side to side as indicated.

\begin{tabular}{|c|c|c|c|c|}
\hline Location & $\begin{array}{c}\text { True } \\
\text { weight }\end{array}$ & $\begin{array}{c}\text { Measured } \\
\text { weight }\end{array}$ & $\begin{array}{c}\text { Absolute } \\
\text { difference }\end{array}$ & $\begin{array}{c}\text { Relative } \\
\text { difference }\end{array}$ \\
\hline \hline front & 2501.5 & 2503.7 & 2.2 & 0.088 \\
\hline front & 2501.5 & 2503.7 & 2.2 & 0.088 \\
\hline front & 2501.5 & 2504.3 & 2.8 & 0.112 \\
\hline front & 2501.5 & 2504.4 & 2.9 & 0.116 \\
\hline front & 2501.5 & 2504.0 & 2.5 & 0.100 \\
\hline front & 2501.5 & 2503.9 & 2.4 & 0.096 \\
\hline back & 2501.5 & 2502.9 & 1.4 & 0.056 \\
\hline back & 2501.5 & 2502.8 & 1.3 & 0.052 \\
\hline back & 2501.5 & 2503.0 & 1.5 & 0.060 \\
\hline back & 2501.5 & 2503.3 & 1.8 & 0.072 \\
\hline back & 2501.5 & 2503.3 & 1.8 & 0.072 \\
\hline back & 2501.5 & 2503.1 & 1.6 & 0.064 \\
\hline \hline side1 & 2501.5 & 2504.1 & 2.6 & 0.104 \\
\hline side1 & 2501.5 & 2503.9 & 2.4 & 0.096 \\
\hline side1 & 2501.5 & 2504.0 & 2.5 & 0.100 \\
\hline side1 & 2501.5 & 2503.9 & 2.4 & 0.096 \\
\hline \hline side2 & 2501.5 & 2503.8 & 2.3 & 0.092 \\
\hline side2 & 2501.5 & 2503.7 & 2.2 & 0.088 \\
\hline side2 & 2501.5 & 2503.8 & 2.3 & 0.092 \\
\hline side2 & 2501.5 & 2503.8 & 2.3 & 0.092 \\
\hline
\end{tabular}

Table 5: Location Changes

Summary values are as follows:

$\begin{array}{cccccc}\text { Location } & \begin{array}{c}\text { N } \\ \text { Rows }\end{array} & \begin{array}{c}\text { Mean } \\ \text { Absolute } \\ \text { difference }\end{array} & \begin{array}{c}\text { Std Dev } \\ \text { Absolute } \\ \text { difference }\end{array} & \begin{array}{c}\text { Mean } \\ \text { Relative } \\ \text { difference }\end{array} & \begin{array}{c}\text { Std Dev } \\ \text { Relative } \\ \text { difference }\end{array} \\ \text { back } & 6 & 1.57 & 0.21 & 0.063 & 0.008 \\ \text { front } & 6 & 2.50 & 0.30 & 0.100 & 0.012 \\ \text { side1 } & 4 & 2.48 & 0.10 & 0.099 & 0.004 \\ \text { side2 } & 4 & 2.28 & 0.05 & 0.091 & 0.002\end{array}$

Table 6: Location Change Summary

The vertical extents of the green diamonds in the following figure represent confidence intervals for the means of the absolute differences. Any two that do not intersect vertically with each other would be considered statistically different. The two side locations and the front do not differ significantly, but the back location is indeed different. The same is shown for the relative differences. 
Oneway Analysis of Absolute difference By Location

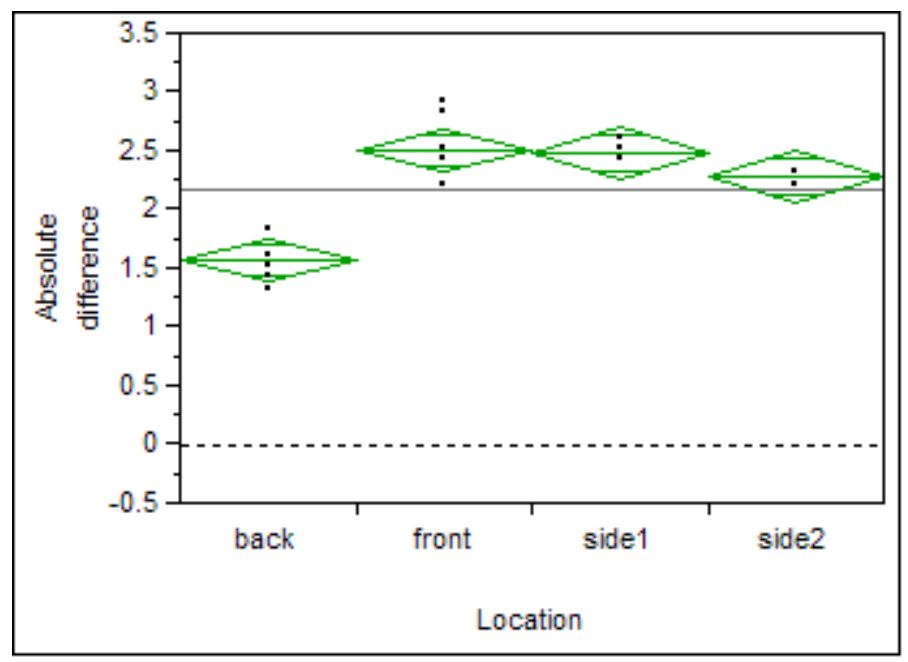

\section{Oneway Anova}

\section{Summary of Fit}

$\begin{array}{lr}\text { Rsquare } & 0.825385 \\ \text { Adj Rsquare } & 0.792644 \\ \text { Root Mean Square Error } & 0.207415 \\ \text { Mean of Response } & 2.17 \\ \text { Observations (or Sum Wgts) } & 20\end{array}$

\section{Analysis of Variance}

$\begin{array}{lrr}\text { Source } & \text { DF } & \text { Sum of Squares } \\ \text { Location } & 3 & 3.2536667 \\ \text { Error } & 16 & 0.6883333 \\ \text { C. Total } & 19 & 3.9420000\end{array}$

$\begin{array}{rrr}\text { Mean Square } & \text { F Ratio } & \text { Prob }>\text { F } \\ 1.08456 & 25.2100 & <.0001\end{array}$

Means for Oneway Anova

$\begin{array}{rrrrrr}\text { Level } & \text { Number } & \text { Mean } & \text { Std Error } & \text { Lower 95\% } & \text { Upper 95\% } \\ \text { back } & 6 & 1.56667 & 0.08468 & 1.3872 & 1.7462 \\ \text { front } & 6 & 2.50000 & 0.08468 & 2.3205 & 2.6795 \\ \text { side1 } & 4 & 2.47500 & 0.10371 & 2.2552 & 2.6948 \\ \text { side2 } & 4 & 2.27500 & 0.10371 & 2.0552 & 2.4948\end{array}$


Oneway Analysis of Relative difference By Location

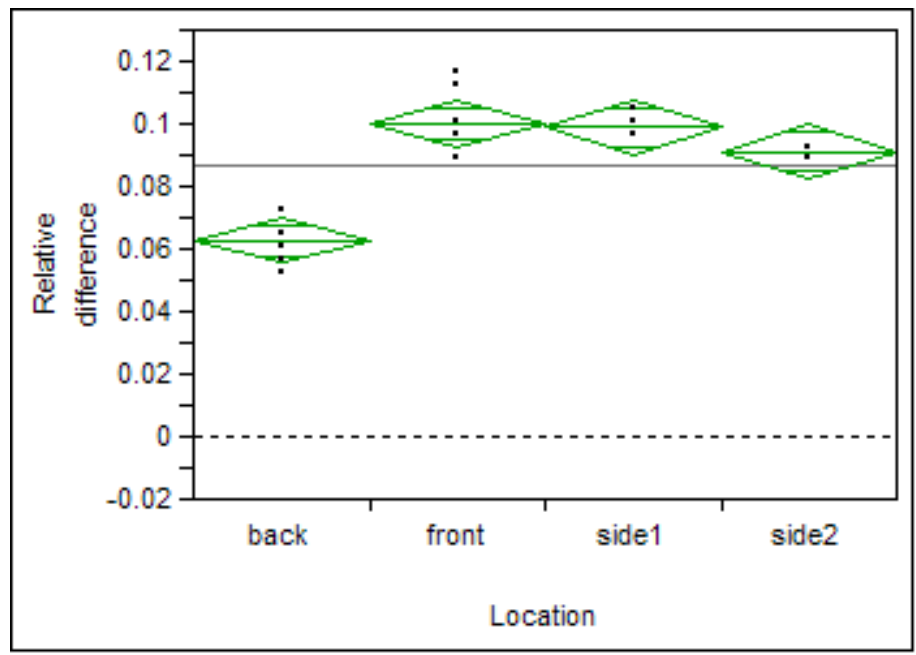

\section{Oneway Anova}

\section{Summary of Fit}

$\begin{array}{lr}\text { Rsquare } & 0.825385 \\ \text { Adj Rsquare } & 0.792644 \\ \text { Root Mean Square Error } & 0.008292 \\ \text { Mean of Response } & 0.086748 \\ \text { Observations (or Sum Wgts) } & 20\end{array}$

\section{Analysis of Variance}

$\begin{array}{lrrrrr}\text { Source } & \text { DF } & \text { Sum of Squares } & \text { Mean Square } & \text { F Ratio } & \text { Prob }>\text { F } \\ \text { Location } & 3 & 0.00519963 & 0.001733 & 25.2100 & <.0001 \\ \text { Error } & 16 & 0.00110001 & 0.000069 & & \\ \text { C. Total } & 19 & 0.00629964 & & & \end{array}$

\section{Means for Oneway Anova}

$\begin{array}{lrrrrr}\text { Level } & \text { Number } & \text { Mean } & \text { Std Error } & \text { Lower 95\% } & \text { Upper 95\% } \\ \text { back } & 6 & 0.062629 & 0.00339 & 0.05545 & 0.06981 \\ \text { front } & 6 & 0.099940 & 0.00339 & 0.09276 & 0.10712 \\ \text { side1 } & 4 & 0.098941 & 0.00415 & 0.09015 & 0.10773 \\ \text { side2 } & 4 & 0.090945 & 0.00415 & 0.08216 & 0.09973\end{array}$

Table 7: Oneway Analysis of Absolute Difference by Location 


\subsection{Environmental Effects}

The final test involved the impact of environmental changes. Ice bags were placed on the scale platform, with the ice tare weight subtracted from the weighing results. Alternatively a space heater was placed near the scale platform. The amount of time that these environmental influences were present was recorded as successive weighings were made. The rather dramatic impacts are shown in the following.

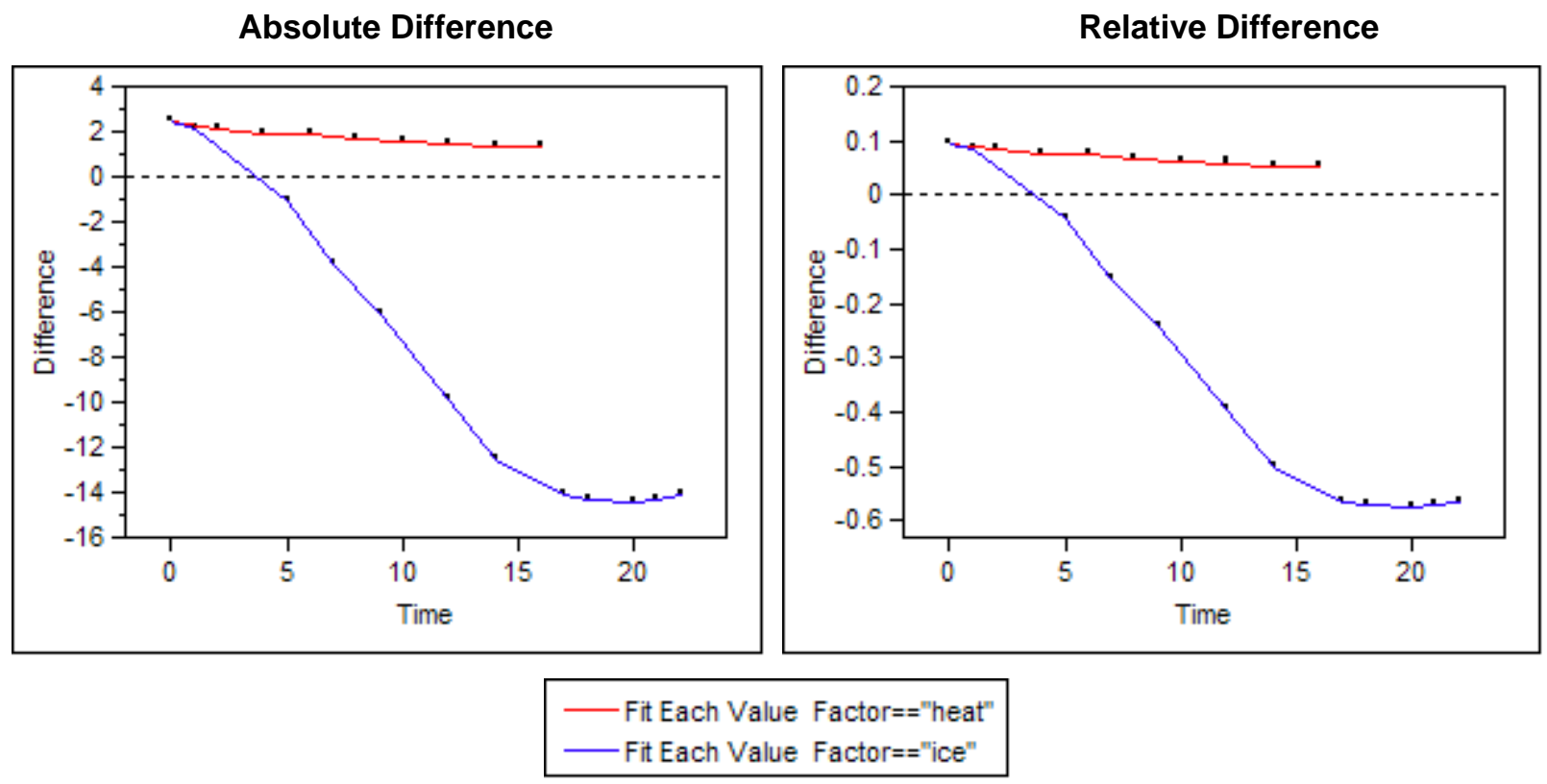

Table 8: Temperature Effects

The left figure shows the absolute difference changes over time caused by ice (blue curve) and heat (red curve); the right figure is the same for relative differences. Horizontal axes are the time in minutes that the effect was applied.

For the absolute differences, a persistent positive bias is again shown under the heat case, but it does decrease slightly over time, possibly as the heater impact is felt. The effects are much more dramatic for the ice impact. In that case, the approximately 2.5 pound absolute difference positive bias is eventually decreased to a negative bias of about 14 pounds after about 15 minutes, after which the weighings remain stable. These results are so dramatic that no statistical summary of "significant differences" is needed.

Relative difference results show the similar pattern with an initial $0.1 \%$ positive bias eventually decreasing to nearly a negative $0.6 \%$ bias.

Clearly such environmental factors need to be reasonably controlled in a production environment. It was suggested that in opening and closing a bay door in the study area, with considerably colder temperatures outside than indoors, the study might have been impacted, in particular in the initial generation of the true weights. This could have been the source of the persistent bias observed. 


\subsection{References}

National Institute of Standards and Technology, NIST Handbook 44: Specifications, Tolerances and Other Technical Requirements for Weighing and Measuring Devices, 2007.

ESARDA. International Target Values 2000 for Measurement Uncertainties in Safeguarding Nuclear Materials, ESARDA Bulletin No. 31, 2000.

American National Standard for Nuclear Materials-Mass Calibration Techniques for Control, ANSI N15.18.1988, American National Standards Institute,1989.

Fainberg, A and D Gordon BNL, Dermendjiev E and D Terrey IAEA, Mitchell R U.S. National Bureau of Standards, A Portable Load-Cell Based System for Weighing UF ${ }_{6}$ Cylinders, International Symposium on Recent Advances in Nuclear Material Safeguards, Vienna Austria 8-12 November 1982. 